\title{
Fractionation of Lignocellulosic Biomass by Selective Precipitation from Ionic Liquid Dissolution
}

\author{
Marta Lara-Serrano, Silvia Morales-delaRosa, Jose M. Campos-Martín *(i) and Jose L. G. Fierro \\ Energy and Sustainable Chemistry Group (EQS), Instituto de Catálisis y Petroleoquímica, CSIC, c/Marie Curie 2 \\ Cantoblanco, 28049 Madrid, Spain; m.lara.serrano@csic.es (M.L.-S.); smorales@icp.csic.es (S.M.-d.); \\ jlgfierro@icp.csic.es (J.L.G.F.) \\ * Correspondence: jm.campos@csic.es
}

Received: 15 April 2019; Accepted: 30 April 2019; Published: 7 May 2019

\begin{abstract}
We propose the treatment of barley straw with 1-ethyl-3-methylimidazolium acetate [EMIMAcO] ionic liquids (ILs) and subsequent precipitation with antisolvent mixtures, thus allowing the separation of the sugar-rich fractions (cellulose and hemicellulose) from the lignin fraction. For this purpose, different concentration ranges of acetone:water antisolvent mixtures were studied. In all cases, a high recovery percentage and a high and effective separation of fractions was achieved for 1:1 acetone:water. The fractionated lignocellulosic compounds were studied by using infrared spectroscopy, scanning electron microscopy and ${ }^{1} \mathrm{H}$ nuclear magnetic resonance characterization techniques. This method allows the possibility of reusing IL, confirming the versatility of the established method. The fraction rich in cellulose and hemicellulose was subjected to acid hydrolysis $\left(0.2 \mathrm{~mol} / \mathrm{L} \mathrm{H}_{2} \mathrm{SO}_{4}\right)$ for $5 \mathrm{~h}$ at $140{ }^{\circ} \mathrm{C}$, obtaining a yield of total reducing sugars of approximately $80 \%$, much higher than those obtained in non-pretreated samples.
\end{abstract}

Keywords: lignocellulosic biomass; ionic liquid; ethyl methyl imidazolium; fractionation; pretreatment; barley straw

\section{Introduction}

The exponential growth of the global population and industrial activity in the last century has compromised the sustainability of life on Earth. The European Commission has set a long-term goal to develop a competitive, resource-efficient and low-carbon economy by 2050 [1]. The bioeconomy will play an important role (2.4 billon $€$ market value in 2015). While fossil resources are the major source of energy and chemicals, biomass will eventually be the most prominent source. Cellulose, hemicelluloses and lignin are the most abundant biopolymers on Earth [2]. These biopolymers are the major components of the plant cell wall, where they are present in a dense ordered matrix and are known as lignocellulose [3,4]. Biomass lignocellulosic used as a feedstock may contain also minor components like proteins and other nitrogen containing materials, non-structural material and inorganic material (ashes) structural or extractable [5]. Cellulose is a linear polymer of glucose units with $\beta-(1 \rightarrow 4)$ links that form a cellulose chain [6-8], and cellulose chains form fibers via $\mathrm{H}$-bonds. Cellulose can be present in a crystalline or amorphous structure, which determines its resistance to hydrolysis $[9,10]$. In contrast to cellulose, the chemical composition of hemicelluloses differs between lignocellulose sources [3]. Lignin is a complex heterogeneous branched polymer that consists of 4-phenylpropane units linked by ether and carbon-carbon alkyl-aryl and aryl-aryl linkages [11]. Various linkages can also exist between lignin and cellulose or hemicelluloses in so-called 'lignin-carbohydrate complexes'. Lignocellulosic biomass conversion requires, almost unavoidably, a pretreatment step, which can be physical, chemical, biochemical, biological or a combination thereof. Pretreatment can reduce the particle size, improve the porosity, alter the cellulose crystallinity and 
fractionate the lignocellulose [10,12-17]. The presence of lignin is considered to be a major barrier to achieving efficient cellulosic bioconversion because of its negative interaction with the biocatalyst during enzymatic hydrolysis and microbial fermentation [18,19]. Lignin acts as a cement around cellulose fibrils, and it is difficult to separate the two components. Typically, harsh conditions are used, causing chemical and structural changes [20]. Once lignin is isolated as a solid (technical lignin), the resulting material is even more recalcitrant than its native state. One of the more interesting lignocellulosic residues are barley wastes. These residues are the second largest biomass feedstock in Europe [21,22]. The estimated amounts of environmental sustainable of barley straw in the European Union for 2030 are 25 million tons [23].

Ionic liquids (ILs) are effective in solubilizing crystalline cellulose and lignocellulosic biomass [24-32], and dissolved cellulose can be regenerated by precipitation with antisolvents. Interestingly, regenerated cellulose shows lower crystallinity and enhanced subsequent hydrolysis rates [33,34]. ILs can also deconstruct and fractionate lignocellulose. Once lignocellulosic biomass is dissolved, it can be fractionated into its principal components by the addition of antisolvents, which leads to the selective precipitation of lignin, cellulose or hemicellulose [35-41]. There is a plethora of studies of IL dissolution of lignocellulosic biomass, where ionic liquids of the imidazolium type are the best solvents [33,42-47]. Among them 1-ethyl-3-methylimidazolium acetate [EMIMAcO] is the most popular, because of his physical properties (low boiling point and viscosity) and chemical properties, absence of halogen as an anion, is not corrosive and practically no reactive with the biomass [30,48-54].

In this work, we studied the dissolution of barley straw in [EMIMAcO] and subsequent precipitation with different concentrations of water:acetone mixtures to improve the fractionation of lignocellulosic biomass. This combination may be interesting because the presence of water favors the precipitation of all the main components of biomass (cellulose, hemicellulose and lignin), while acetone does not favor the precipitation of lignin, according to the literature [55].

\section{Materials and Methods}

All chemicals were of reagent grade and purchased from Meck Milipore Sigma-Aldrich (Darmstadt, Germany), except xylan (from beechwood), which was purchased from TCI-Europe, N. V. (Zwijndrecht, Belgium) and used without any further purification. The lignocellulosic biomass (barley straw) used was provided and characterized by the Biofuels Unit of CIEMAT.

Analysis of Barley Straw. The methods of characterization of barley straw are procedures adapted from the standard methods for the analysis of biomass published by the National Renewable Energy Laboratory (NREL; Colorado, USA) [56]. Determinations of extractives were made in quadruplicate, and component analysis of the collected samples was performed in triplicate. The average values for dried samples are summarized in Table 1.

Table 1. Composition analysis (wt.\%) of samples of barley straw dried at $105^{\circ} \mathrm{C}$.

\begin{tabular}{ll}
\hline Extractives & $\mathbf{1 3 . 3 7}$ \\
\hline Aqueous & $10.99 \pm 0.31$ \\
Organic & $2.38 \pm 0.26$ \\
\hline Cellulose & $\mathbf{3 1 . 0 9} \pm \mathbf{1 . 2 5}$ \\
\hline Hemicellulose & $\mathbf{2 7 . 2 3} \pm \mathbf{0 . 4 4}$ \\
\hline Xylose & $22.06 \pm 0.47$ \\
Galactose & $1.3 \pm 0.01$ \\
Arabinose + Mannose & $3.87 \pm 0.03$ \\
\hline Insoluble Lignin & $\mathbf{1 6 . 6 7} \pm \mathbf{1 . 1 3}$ \\
\hline Soluble Lignin & $\mathbf{2 . 1} \pm \mathbf{0 . 0 3}$ \\
\hline Ash & $\mathbf{3 . 8 9} \pm \mathbf{0 . 0 5}$ \\
\hline Acetyl Goups & $\mathbf{1 . 7 2} \pm \mathbf{0 . 0 2}$ \\
\hline
\end{tabular}


Dissolution and Precipitation. A total of $0.50 \mathrm{~g}$ of barley straw was dissolved in $9.50 \mathrm{~g}$ of ionic liquid (1-ethyl-3-methylimidazolium acetate, [EMIMAcO]) at $105^{\circ} \mathrm{C}$ in a Mettler-Toledo Easy Max $102^{\circledR}$ reactor equipped with mechanical stirring at atmospheric pressure $[34,47,57,58]$. Complete visual dissolution was observed at $3.5 \mathrm{~h}$, and then the carbohydrate-rich material was precipitated by the addition of an antisolvent $(25 \mathrm{~mL})$. The antisolvents tested were water, acetone and mixtures thereof. The obtained Solid I was separated by vacuum filtration with a nylon membrane $(20 \mu \mathrm{L})$ such that the lignin dissolved in the ionic liquid (IL) was not retained in the filter. The filtered solid, which was rich in carbohydrates, was washed several times with distilled water to remove the remaining IL. Solid II (carbohydrate-free lignin) was recovered by evaporation of acetone, vacuum filtration with a nylon membrane $(0.2 \mu \mathrm{L})$ and washing with distilled water (Figure 1).

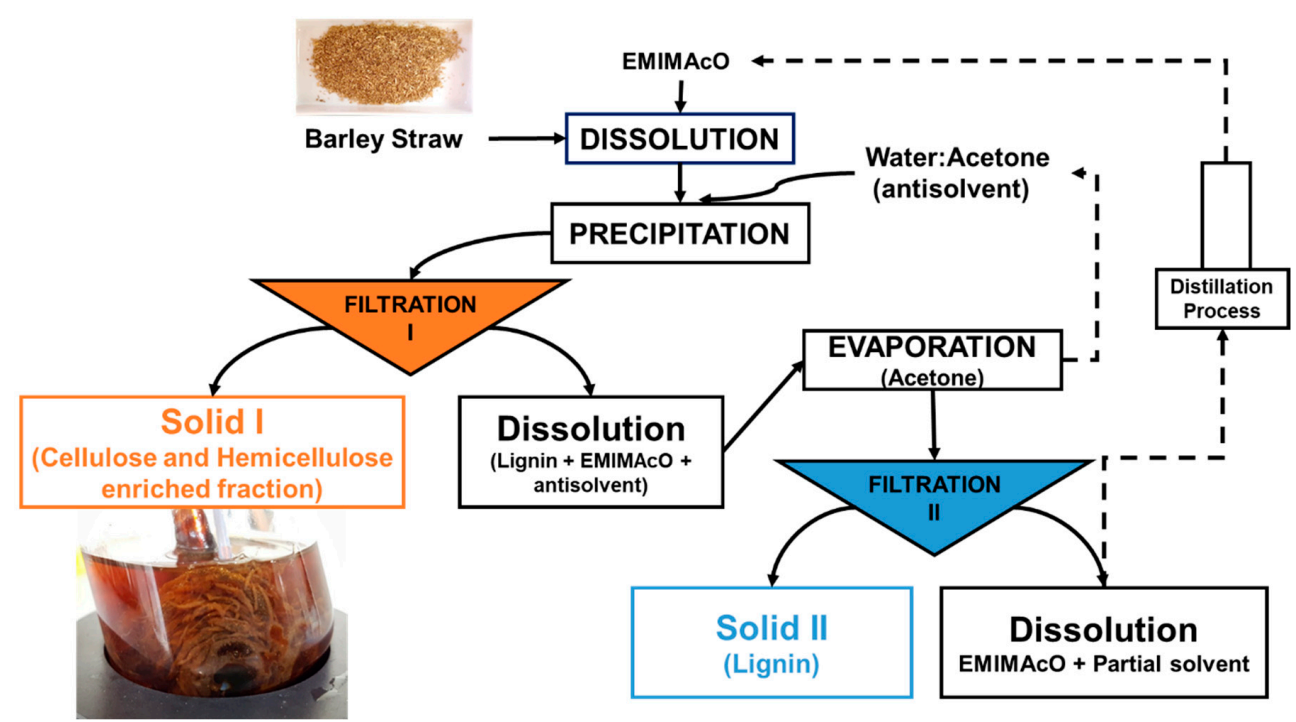

Figure 1. The scheme of the process of dissolution of barley straw in [EMIMAcO] and subsequent precipitation with a water:acetone antisolvent mixture.

The scheme of the dissolution process of barley straw in the ionic liquid [EMIMAcO] and subsequent precipitation with mixtures of water:acetone is shown in Figure 1, which shows the methods used to obtain the two types of solids. Solid I (rich in cellulose and hemicellulose) was obtained after Filtration I, and Solid II (rich in lignin) was obtained after Filtration II from the liquid obtained in the first filtration after the evaporation of acetone.

Hydrolysis. Hydrolysis reactions were carried out batchwise in a magnetically stirred $100 \mathrm{~mL}$ thermostatic Teflon-lined steel Berghof reactor equipped with a pressure addition funnel [33,34,57]. In a typical run, $0.5 \mathrm{~g}$ of barley straw and $40 \mathrm{~mL}$ of water were mixed in the reactor, the suspension was heated to the reaction temperature $\left(140{ }^{\circ} \mathrm{C}\right)$, and $10 \mathrm{~mL}$ of $\mathrm{H}_{2} \mathrm{SO}_{4}(0.2 \mathrm{~mol} / \mathrm{L})$ was added to the reactor. These are the optimal conditions obtained from previous works [33,57]. The reaction time was measured from this moment; the reaction was stopped at $5 \mathrm{~h}$, and the suspension was quickly cooled. Aliquots were periodically taken from the reactor. The solution was filtered off and washed with distilled water, and finally, the solid was dried at $80^{\circ} \mathrm{C}$ overnight. The amount of solid isolated was determined by weighing. The liquid was analyzed by HPLC (Agilent Technologies (Santa Clara, California, USA) HPLC 1200 and 1260 series). The chromatographic separations were carried out in a Hi-PLEX $\mathrm{H}$ column at $60^{\circ} \mathrm{C}$ using $0.6 \mathrm{~mL} / \mathrm{min}$ sulfuric acid aqueous solution $(0.01 \mathrm{M})$ as the mobile phase and in a Hi-Plex Pb column at $90^{\circ} \mathrm{C}$ using $0.6 \mathrm{~mL} / \mathrm{min}$ water solution for HPLC as the mobile phase and a refractive index detector. This method avoids the analysis of sugars (glucose and xylose) and the secondary products (5-hydroxy-methylfurfural, furfural and levulinic acid). Identification and quantification of the components was performed by comparison of retention times and using internal calibration curves by pattern compounds. 
FTIR. Infrared spectra of the solids were recoded with a Jasco FT/IR-6300 spectrophotometer with $\mathrm{KBr}$ pellets made of $5 \%$ sample. A total of 180 cumulative scans were performed with a resolution of $4 \mathrm{~cm}^{-1}$ in the frequency range of $4000-800 \mathrm{~cm}^{-1}$ in absorption mode.

NMR. ${ }^{1} \mathrm{H}$ Nuclear magnetic resonance (NMR) spectra were obtained in DMSO- $d_{6}$ and were recorded using a Bruker Advance at $300 \mathrm{MHz}$ referenced to DMSO at $2.50 \mathrm{ppm}$.

Scanning electron microscopy (SEM). SEM micrographs of untreated barley straw and barley straw pretreated with IL were collected with a Hitachi S-3000 N instrument. The samples were treated with increasing concentrations of ethanol to fix the structure and to dehydrate the samples. The samples were metallized in a Balzers SCD 004 gold sputter coater and were sputter-coated with a thin layer of gold.

X-ray diffraction (XRD). XRD profiles of samples were recorded with an X'Pert Pro PANalitical diffractometer equipped with a $\mathrm{CuK} \alpha$ radiation source $(\lambda=0.15418 \mathrm{~nm})$ and $X^{\prime}$ Celerator detector based on real-time multiple-strip (RTMS) detection. The samples were ground and placed on a stainless steel plate. The diffraction patterns were recorded in steps over a range of Bragg angles $(2 \theta)$ between $4^{\circ}$ and $90^{\circ}$ at a scanning rate of $0.02^{\circ}$ per step and an accumulation time of $50 \mathrm{~s}$. Diffractograms were analyzed with $X^{\prime}$ Pert HighScore Plus software.

\section{Results and Discussion}

\subsection{Effect of the Water:Acetone Ratio}

The barley straw dissolved in [EMIMAcO] was reconstructed by the addition of an antisolvent. The antisolvents employed were mixtures of water:acetone (W:A) with different mass ratios: 1:0, 2:1, 1.5:1, 1:1, 1:1.5, 1:2 and 0:1. The solid precipitated after the addition of the solvent was labeled "Solid $\mathrm{I}$ ", and a second solid was obtained after the evaporation of acetone, labeled "Solid II". To evaluate the fractionation ability of the antisolvent employed, the mass of each solid was measured and compared with the theoretical amount that corresponds in Solid I to the sum of cellulose and hemicellulose and in Solid II to lignin. In addition, the recovered in each solid and total biomass was calculated by comparing the sum of the masses recovered in the two filtrations and the sum of cellulose, lignin and hemicellulose present in the biomass added at the beginning of the experiment. The results obtained from precipitation with the different antisolvents are shown in Table 2.

Table 2. Mass balance of matter based on dry barley straw after precipitating the biomass with different water:acetone antisolvent mixtures. The barley straw samples were dissolved in [EMIMAcO]) at 105 ${ }^{\circ} \mathrm{C}$ for $3.5 \mathrm{~h}$.

\begin{tabular}{|c|c|c|c|c|c|c|}
\hline \multirow[b]{2}{*}{ Sample a } & \multirow[b]{2}{*}{ Antisolvent } & \multicolumn{2}{|c|}{$\%$ Solid I } & \multicolumn{2}{|c|}{$\%$ Solid II } & \multirow[b]{2}{*}{$\begin{array}{c}\text { \% Recovered } \\
\text { Biomass }\end{array}$} \\
\hline & & $\begin{array}{c}\text { \% Initial } \\
\text { Biomass }\end{array}$ & $\%$ Expected $^{c}$ & $\begin{array}{c}\% \text { Initial } \\
\text { Biomass }^{b}\end{array}$ & $\%$ Expected $^{\mathrm{c}}$ & \\
\hline WA-1:0 & Water & \multicolumn{4}{|c|}{ No separation found } & $89 \%$ \\
\hline WA-2:1 & Water:Acetone 2:1 & $77.6 \%$ & $113.4 \%$ & $10.4 \%$ & $53.1 \%$ & $88 \%$ \\
\hline WA-1.5:1 & Water:Acetone 1.5:1 & $79.9 \%$ & $112.9 \%$ & $11.1 \%$ & $55.0 \%$ & $91 \%$ \\
\hline WA-1:1 & Water:Acetone 1:1 & $71.2 \%$ & $102.9 \%$ & $17.8 \%$ & $90.0 \%$ & $89 \%$ \\
\hline WA-1:1.5 & Water:Acetone 1:1.5 & $78.6 \%$ & $113.6 \%$ & $10.4 \%$ & $52.5 \%$ & $89 \%$ \\
\hline WA-1:2 & Water:Acetone 1:2 & $78.1 \%$ & $114.2 \%$ & $9.9 \%$ & $50.4 \%$ & $88 \%$ \\
\hline WA-0:1 & Acetone & \multicolumn{4}{|c|}{ No separation found } & $87 \%$ \\
\hline
\end{tabular}

a The samples are called WA-X:Y, where WA refers to "Water:Acetone" and the numbers $X$ and Y indicate the water:acetone ratio used. $\mathrm{b} \%$ of biomass recovered based on the initial mass of cellulose + hemicellulose + lignin present in raw barley straw. ${ }^{\mathrm{c}} \%$ of mass recovered if Solid I is only the sum (cellulose + hemicellulose) and Solid II is the mass of lignin (Table 1).

The total recovered biomass was high, approximately $90 \%$, in all cases, respect the sum of hemicellulose + cellulose + lignin present in the starting barley straw. In Solid II the recovery is between 70 and $80 \%$ while in Solid II is $10-17 \%$, depending on the mixture of antisolvent employed. This effect was also observed in the \% expected which depends also on the mixture employed. When 
pure solvent (water or acetone) was employed, only Solid I was obtained, which implies no separation of components by selective precipitation. However, the properties of the obtained solid were quite different depending on the pure solvent employed. When water was used as an antisolvent, Solid I was easy to manipulate, wash and filter, but in the case of acetone, the solid obtained was very difficult to handle, wash and filter. However, when the antisolvent was a mixture of water:acetone, the presence of two solids (Solid I and Solid II) was observed (Table 2). In all cases, the amount of Solid I was higher than the theoretical sum of cellulose and hemicellulose ( $>100 \%)$, and the amount of Solid II was lower than the theoretical amount of lignin $(<100 \%)$. The values of mass recovered indicate that in Solid I, some lignin was incorporated with the cellulose and hemicellulose. However, these amounts changed with the W:A ratio The most interesting results were obtained for the ratio 1:1, where both Solid I and Solid II were close to $100 \%$. Based on these results, the optimal antisolvent used was the W:A = 1:1 mixture. However, these mass balance calculations do not guarantee that Solid I is a cellulose- and hemicellulose-rich phase and Solid II is lignin or a lignin-rich phase. For this reason, we proceeded to analyze each of the solids obtained.

\subsection{FTIR Analysis}

FTIR spectroscopy has been extensively employed to study the functional groups of cellulose, xylan-like hemicellulose and lignin in the literature. Changes in the composition of Solid I and Solid II were monitored using FTIR. The spectra of Solid I and Solid II are very different. Figure 2 demonstrates that the IR spectra of the raw barley straw, Solid I and Solid II show a broad and intense band in the region of $3800-2600 \mathrm{~cm}^{-1}$, which is associated with $\mathrm{OH}$ groups and their interactions with water molecules via $\mathrm{H}$-bridging bonds [59]. In addition, a set of overlapping peaks appears between 3000 and $2800 \mathrm{~cm}^{-1}$ due to the stretching vibration modes of $\mathrm{C}-\mathrm{H}$ bonds. The relative intensity of these peaks increases in Solid II with respect to the spectra of raw barley straw and Solid I, indicating an enrichment of lignin, the component containing a greater proportion of $\mathrm{C}-\mathrm{H}$ bonds than $\mathrm{O}-\mathrm{H}$ groups.

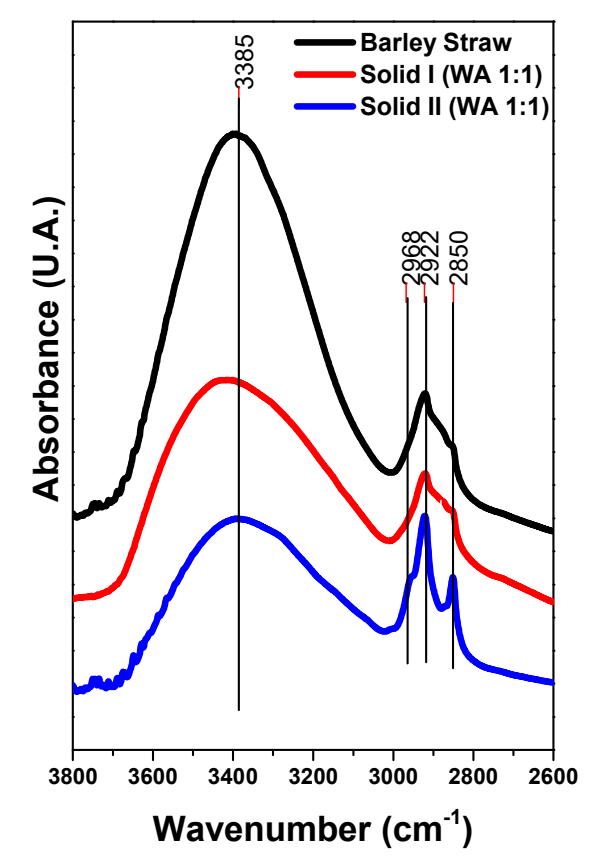

Figure 2. FTIR spectra of Solid I, Solid II and raw barley straw.

The spectra of Solid I, Solid II and references of commercial cellulose, xylan and lignin are displayed in the region between 1800 and $800 \mathrm{~cm}^{-1}$ in Figures 3 and 4, respectively. The bands are assigned to the characteristic bending or stretching modes of different specific groups of lignocellulosic biomass in the "fingerprint" region. The peak structure of this region is quite complicated, but the peaks can be assigned 
as follows [60-63]: $1735 \mathrm{~cm}^{-1}$ indicates unconjugated $\mathrm{C}=\mathrm{O}$ in xylans (hemicellulose); $1653 \mathrm{~cm}^{-1}$ indicates absorbed O-H and conjugated C-O in lignin; $1593 \mathrm{~cm}^{-1}$ and $1508 \mathrm{~cm}^{-1}$ indicate $\mathrm{C}=\mathrm{C}$ skeletal vibrations (aromatic ring) in lignin; $1457 \mathrm{~cm}^{-1}$ and $1420 \mathrm{~cm}^{-1}$ indicate $\mathrm{C}-\mathrm{H}$ deformation in lignin and carbohydrates; $1375 \mathrm{~cm}^{-1}$ indicates $\mathrm{C}-\mathrm{H}$ deformation in cellulose and hemicellulose; $1336 \mathrm{~cm}^{-1}$ and $1318 \mathrm{~cm}^{-1}$ indicate $\mathrm{C}-\mathrm{H}$ vibration in cellulose and C-O vibration in syringyl derivatives; $1264 \mathrm{~cm}^{-1}$ indicates guaiacyl ring breathing, $\mathrm{C}-\mathrm{O}$ stretching in lignin and C-O linkages in guaiacyl aromatic methoxyl groups; $1157 \mathrm{~cm}^{-1}$ indicates $\mathrm{C}-\mathrm{O}-\mathrm{C}$ vibration in cellulose and hemicellulose; $1118 \mathrm{~cm}^{-1}$ indicates aromatic skeletal vibration; 1085 and $1035 \mathrm{~cm}^{-1}$ indicate $\mathrm{C}-\mathrm{O}$ deformation in aliphatic ether and guaiacyl aromatic methoxyl groups, respectively; $1048 \mathrm{~cm}^{-1}$ indicates $\mathrm{C}-\mathrm{O}$ stretching in cellulose and hemicellulose; and $896 \mathrm{~cm}^{-1}$ indicates $\mathrm{C}-\mathrm{H}$ deformation in cellulose [60-63].

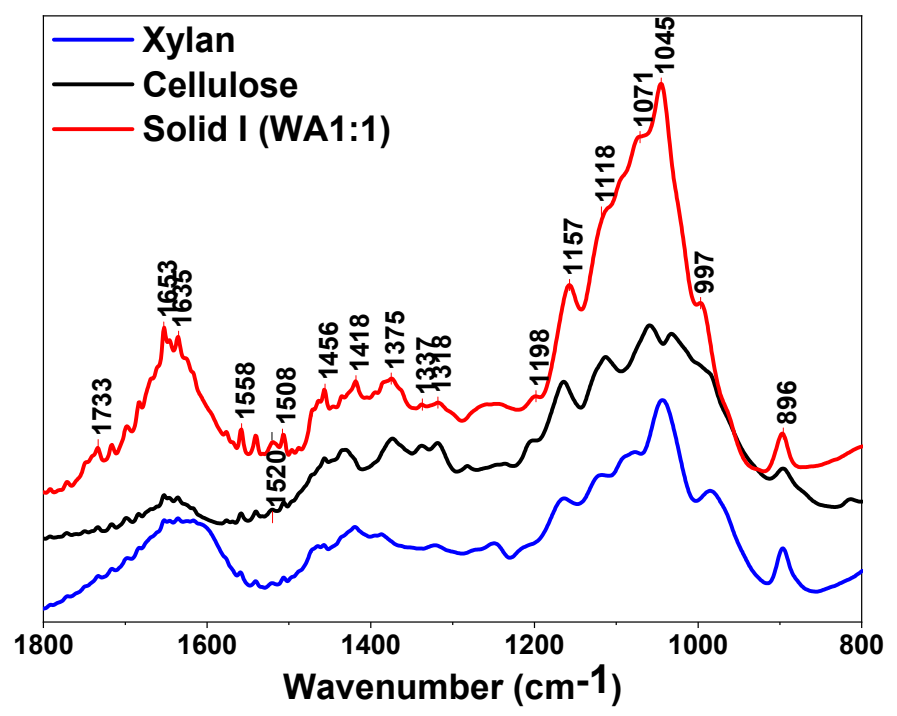

Figure 3. FTIR spectra of Solid I, commercial cellulose and xylan.

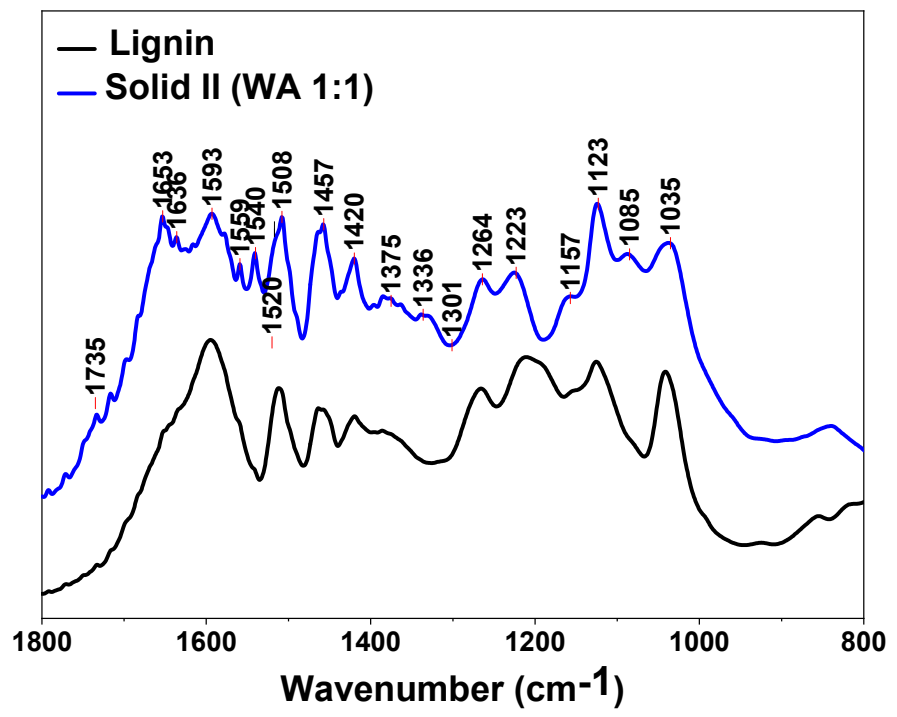

Figure 4. FTIR spectra of Solid II and commercial lignin.

The presence of a peak at $1508 \mathrm{~cm}^{-1}$ is usually taken as an indication of the presence of lignin, especially when a weak band at $1520 \mathrm{~cm}^{-1}$ is present [63] (Figure 4), whereas the 1735, 1157, 1048 and $897 \mathrm{~cm}^{-1}$ peaks are characteristic of polysaccharides $[60,63]$. There are some weak bands typical of lignin in Figure 4, confirming that low amounts of lignin are retained in Solid I, as can be deduced from the mass balance data (Table 2). However, no peaks attributed to polysaccharides are evident in 
the spectrum of Solid II (Figure 4). In summary, the spectrum of Solid I is similar to that corresponding to the pure cellulose reference, whereas the spectrum of Solid II is similar to that corresponding to lignin. These data indicate that selective precipitation occurred, except for small amounts of lignin incorporated into Solid I.

\subsection{NMR Analysis}

The Solid I and Solid II samples were analyzed by ${ }^{1} \mathrm{H}$ magnetic resonance in DMSO- $d_{6}$ solution and were compared with commercial reference materials of cellulose, xylans and lignin (Figures 5-9). The spectra of Solid I and Solid II are very different.

The ${ }^{1} \mathrm{H}$ spectrum of Solid I (Figure 5), obtained after the first filtration, was compared with the reference ${ }^{1} \mathrm{H}$ spectra of commercial samples of cellulose and hemicellulose (Figures 6 and 7). A combination of the structural skeletons of both sugars in the range of $5.5-3.5 \mathrm{ppm}$ is observed $[64,65]$. This observation indicates that Solid I is mainly a combination of carbohydrates; however, in the spectrum of Solid I, peaks corresponding to aromatic rings at 7.8 and $7.7 \mathrm{ppm}$ and aldehyde at 9.0 ppm, associated with lignin, were observed. These data are consistent with the mass balance, which indicated that the mass recovered in the first filtration was slightly higher than expected. This analysis confirms that a small amount of lignin was present in Solid I.

The ${ }^{1} \mathrm{H}$ spectra of Solid II (Figure 8) and commercial lignin (Figure 9) are quite similar. In both spectra, signals appear at $9.2 \mathrm{ppm}$, corresponding to the strong shielding among guaiacyl groups, although a greater intensity is observed in the ${ }^{1} \mathrm{H}$ spectrum of Solid II than that of the reference lignin. Methoxyl group protons are in the region of 4.0-3.4 ppm, very close to the water protons of aldehyde groups. signals in the region of 8.5-8.0 ppm correspond to the phenolic hydroxyl protons of lignin, and in the range of 8.0-6.0, the observed proton signals belong to the aromatic rings and vinyl protons of syringyl and guaiacyl. In the range of $6.0-4.0 \mathrm{ppm}$, signals of protons belonging to $\alpha, \beta$, and $\gamma$ saturated carbons of $\beta-O-4, \beta-5$ and $\beta-\beta$ linkages appear because the lignin and Solid II are not completely dry and the DMSO-d6 is not $100 \%$ pure [66,67]. Finally, in the range of $2.0-1.0 \mathrm{ppm}$, the signals correspond to $\mathrm{CH}_{2}$, the aliphatic protons belonging to methyl or methylene groups, while the signals between 1.0 and $0.8 \mathrm{ppm}$ were attributed to the protons in saturated aliphatic chains in lignin [66]. In summary, Solid II is essentially lignin. These observations are in agreement with the IR characterization: Solid I is a carbohydrate-rich solid with a small amount of lignin, and Solid II is essentially lignin.

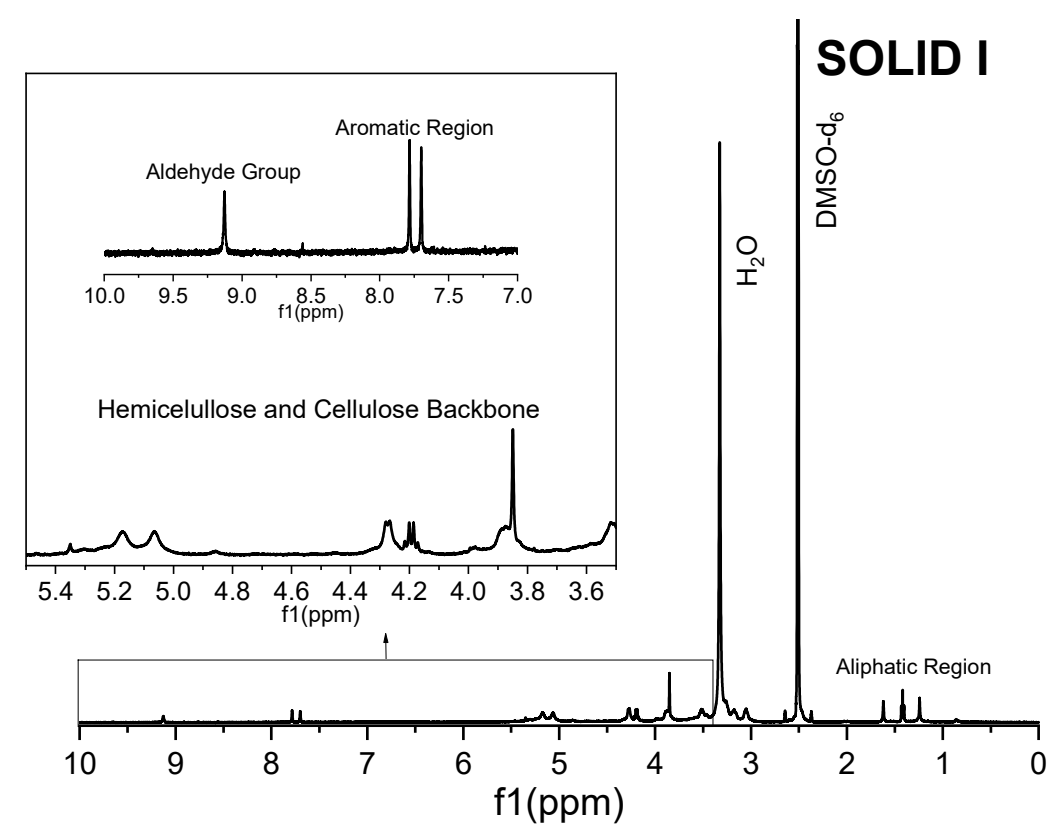

Figure 5. ${ }^{1} \mathrm{H}$ NMR spectrum of Solid I. 


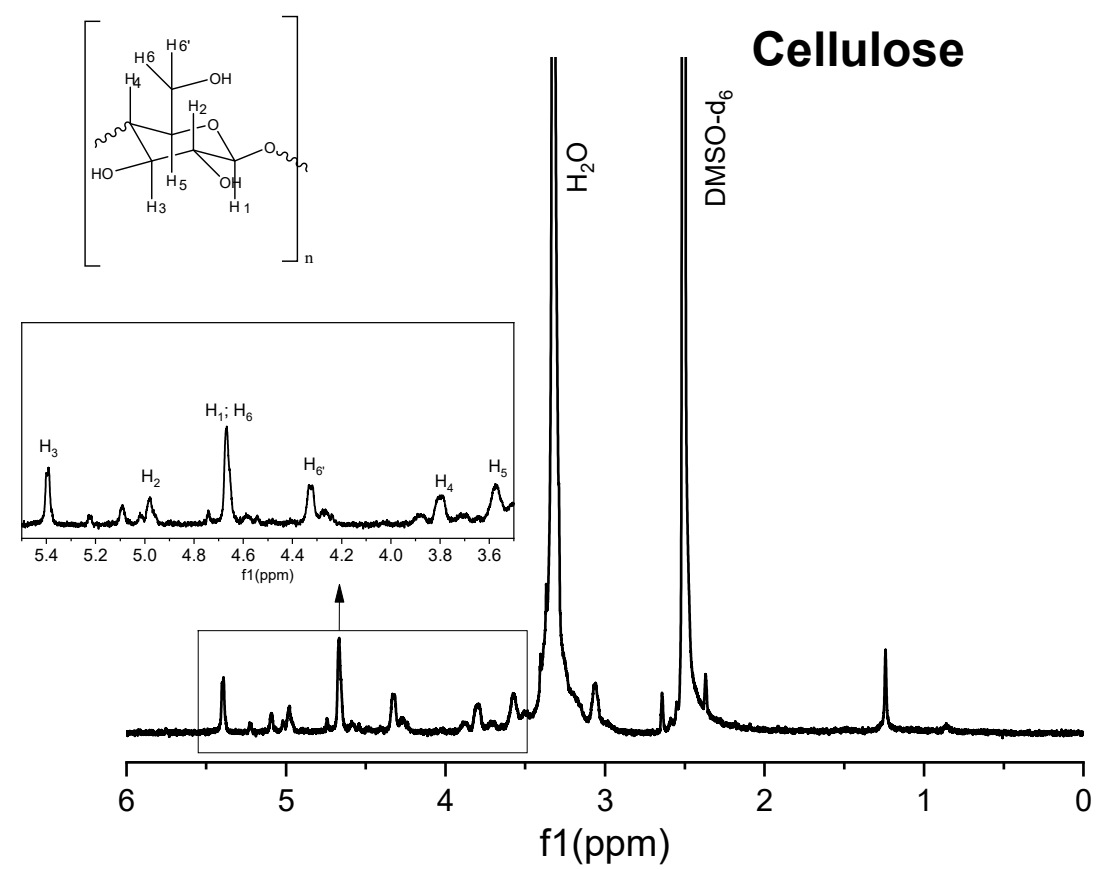

Figure 6. ${ }^{1} \mathrm{H}$ nuclear magnetic resonance (NMR) spectrum of commercial cellulose.

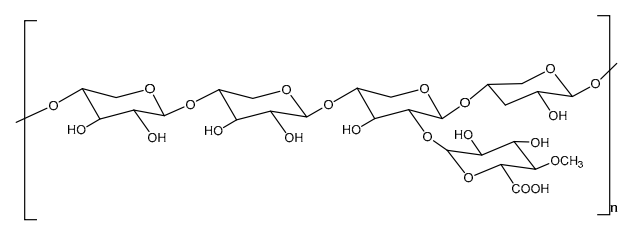

\section{Hemicellulose}

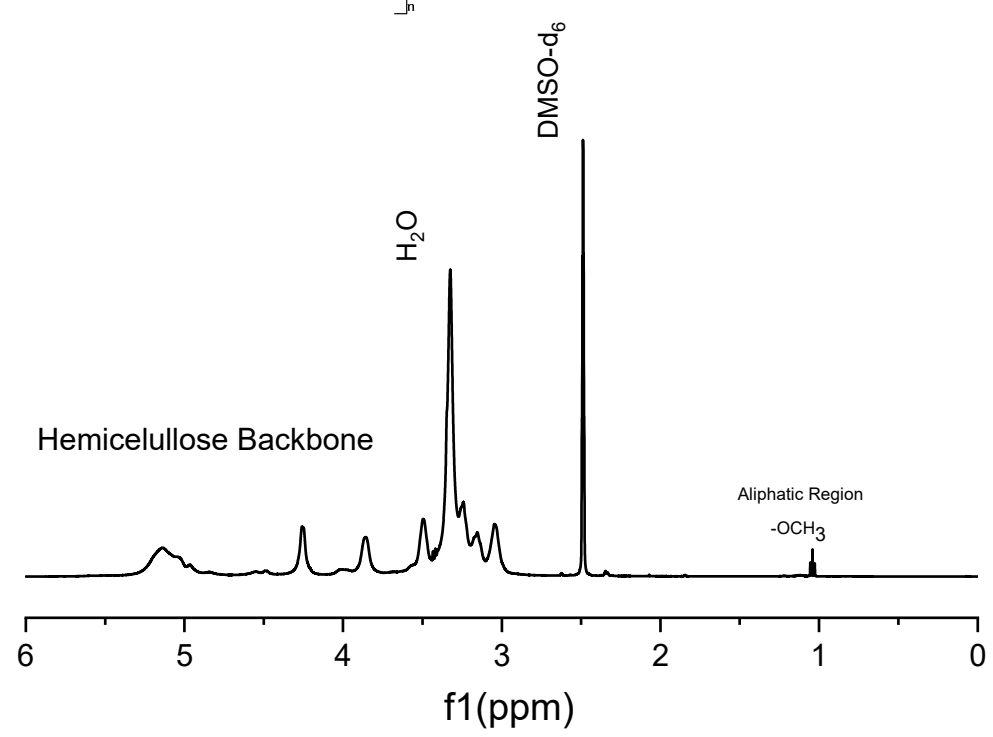

Figure 7. ${ }^{1} \mathrm{H}$ NMR spectrum of commercial xylans. 


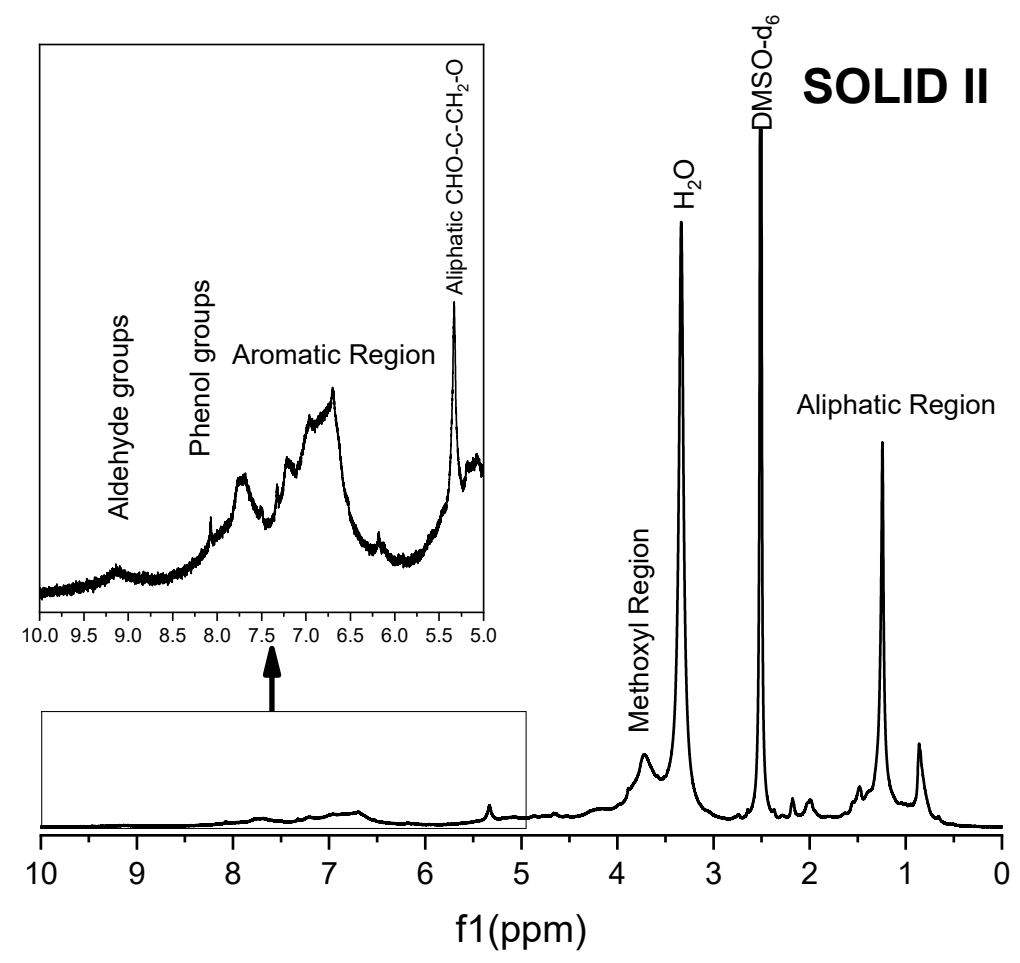

Figure 8. ${ }^{1} \mathrm{H}$ NMR spectra of Solid II.

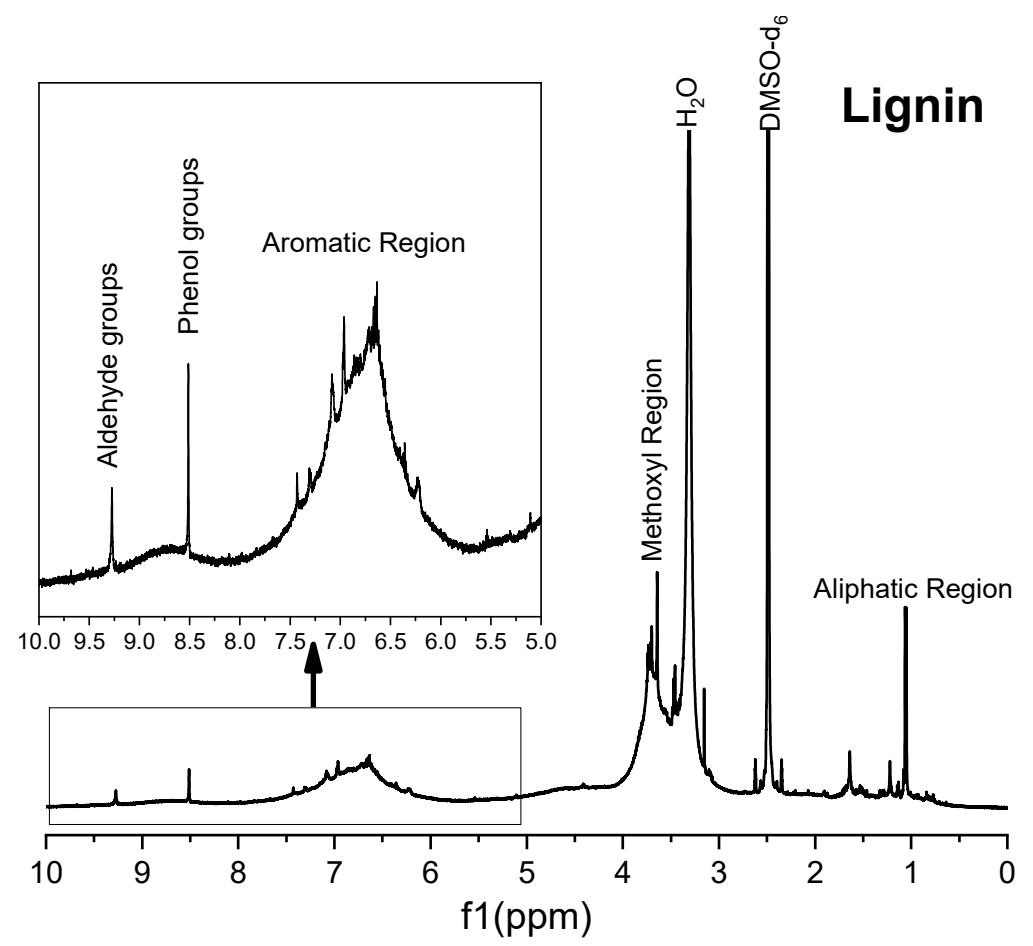

Figure 9. ${ }^{1} \mathrm{H}$ NMR spectrum of commercial lignin.

\subsection{X-ray Diffraction}

X-ray diffraction was employed to analyze the crystallinity of the materials. XRD profiles of the original barley straw and Solid I are depicted in Figure 10. The diffractogram of the original barley straw shows peaks typical of the crystalline structure of cellulose $[57,68]$. A prominent peak at $23^{\circ}$ corresponds to the (200) reflection, and a wide peak from $15-17^{\circ}$ represents the combination of the two reflections corresponding to $(110)$ and $(11 \overline{0})$. The pattern of Solid I, obtained after treating barley 
straw and selective precipitation, showed that the crystallinity was lost because these reflections were not found; the only peak found was at $21^{\circ}$. In this sample, almost no diffraction peaks are observed, indicating the nearly total disappearance of its crystallinity. This study indicates that the original barley straw has a certain crystallinity that is lost after [EMIMAcO] treatment. Other authors have also reported this behavior in different samples of lignocellulosic biomass and cellulose when the samples were treated with ionic liquids $[33,55]$.

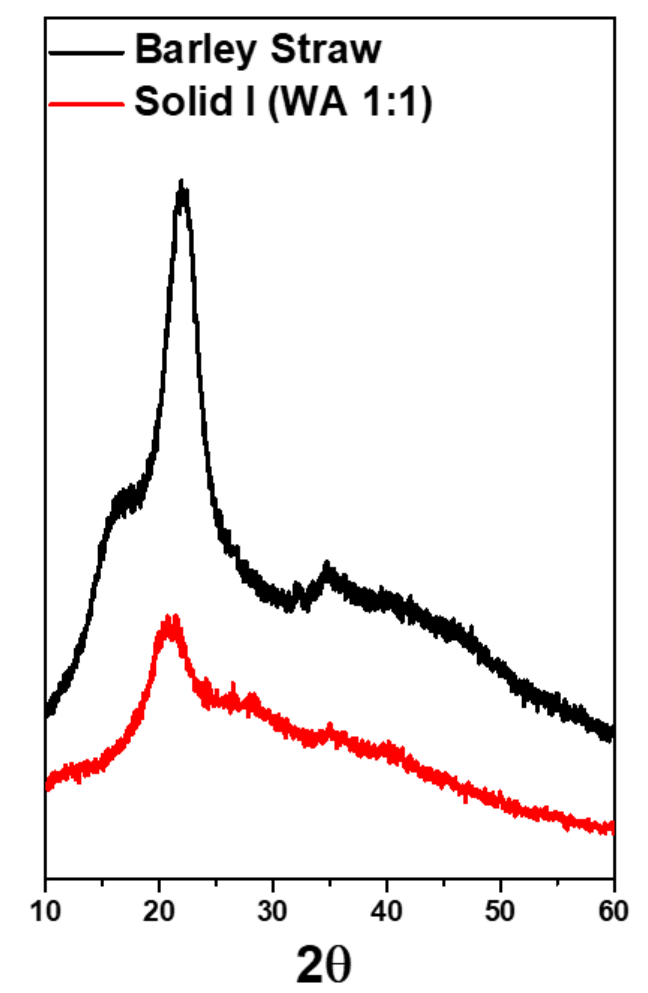

Figure 10. X-ray diffraction (XRD) spectra of raw barley straw and Solid I.

\subsection{Scanning Electron Microscopy (SEM)}

Solid I and raw barley straw were analyzed by SEM. The micrographs show a large difference between the starting sample and the precipitated sample (Figure 11). The sample of original barley straw (Figure 11) shows a regular structure typical of the vascularization of straw. However, the Solid I sample (Figure 11) lost practically all of its vascular structure. In addition, the images with higher magnification indicate that the treated sample was more porous than the original. These morphological changes are compatible with the structural changes observed in X-ray diffraction. The structure of the starting biomass was modified, giving rise to a more amorphous structure, which favors accessibility to the biomass components, making the material easier to transform. Destruction of the structure of lignocellulosic biomass has been observed in previous works [47] by other authors [69] and with other pretreatments [70]. 

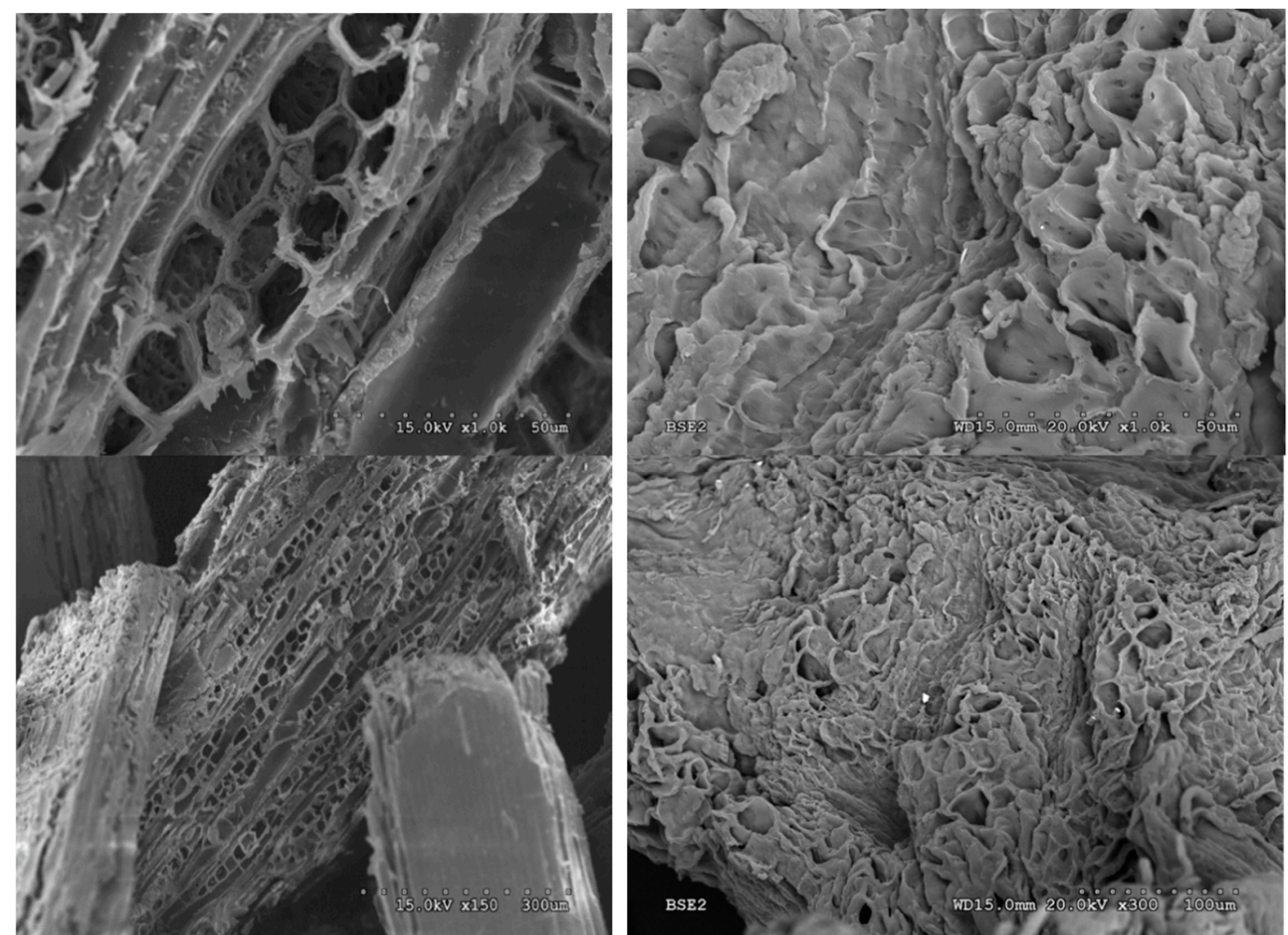

Figure 11. Scanning electron microscopy (SEM) images of raw barley straw (left) and barley straw treated with [EMIMAcO] (Solid I, WA 1:1) (right).

\subsection{Catalytic Activity}

Original barley straw, cellulose and Solid I were subjected to hydrolysis in water media at $140{ }^{\circ} \mathrm{C}$ with $0.2 \mathrm{~mol} / \mathrm{L} \mathrm{H}_{2} \mathrm{SO}_{4}$. In Table 3, a comparison of the conversion values obtained with Solid I, the original barley straw and Avicel cellulose without treatment are shown. The conversion values were calculated by the weight difference between the sample initially added to the reaction and the sample obtained after reaction. The conversion values were different among the three samples studied; the lowest value was obtained for the cellulose sample, while the conversion values were higher for the other two samples. This trend is expected because the most complicated material to hydrolyze is cellulose, and samples of untreated barley straw only contain approximately $31 \%$ cellulose (Table 3 ). In Solid I, impurities of lignin in the sample were not taken into account to avoid complicating the calculations and reduce error since the amount of lignin in the sample was very small. The conversion of $90 \%$ in Solid I appears to be slightly high.

Table 3. Results of conversion obtained after hydrolysis of untreated cellulose, untreated barley straw and barley straw treated (Solid I) with [EMIMAcO]. Reaction conditions: $\mathrm{H}_{2} \mathrm{SO}_{4}(0.2 \mathrm{~mol} / \mathrm{L}), 140{ }^{\circ} \mathrm{C}$ and $5 \mathrm{~h}$.

\begin{tabular}{cc}
\hline Sample & \% Conversion \\
\hline Cellulose & 25 \\
Barley Straw & 83 \\
Solid I & 93 \\
\hline
\end{tabular}

However, the conversion data are not conclusive because the hydrolysis schemes of cellulose and hemicellulose are complicated by consecutive reactions and can lead to the formation of humics and other products. For this reason, it is interesting to analyze the yields of the main products derived from 
glucans, glucose and levulinic acid, and the main products of xylans, xylose and furfural. It should be noted that under these reaction conditions and in aqueous media in the presence of an acid, the concentration of 5-hydroxymethylfurfural is very small because it easily transforms into levulinic acid.

In Figure 12A, the yield of glucose decreases in the following order: Solid I > original barley straw $>$ cellulose. Cellulose gave a very low yield of glucose $(11 \%)$ after $5 \mathrm{~h}$ of reaction. The barley straw sample gave a higher yield of approximately $30 \%$. However, with the Solid I sample, a yield of $65 \%$ was reached, which substantially affects acid hydrolysis to sugars. These glucose yield values follow an order inverse to that of sample crystallinity, as shown in Figure 10. This is because greater crystallinity (order) hinders the breakdown of the $B(1 \rightarrow 4)$-D-glucosidic bonds of cellulose because they are less accessible. However, treatment that reduces the crystallinity and increases the accessibility of said bonds favors hydrolysis, giving rise to higher yields of glucose [33,34,46,71].
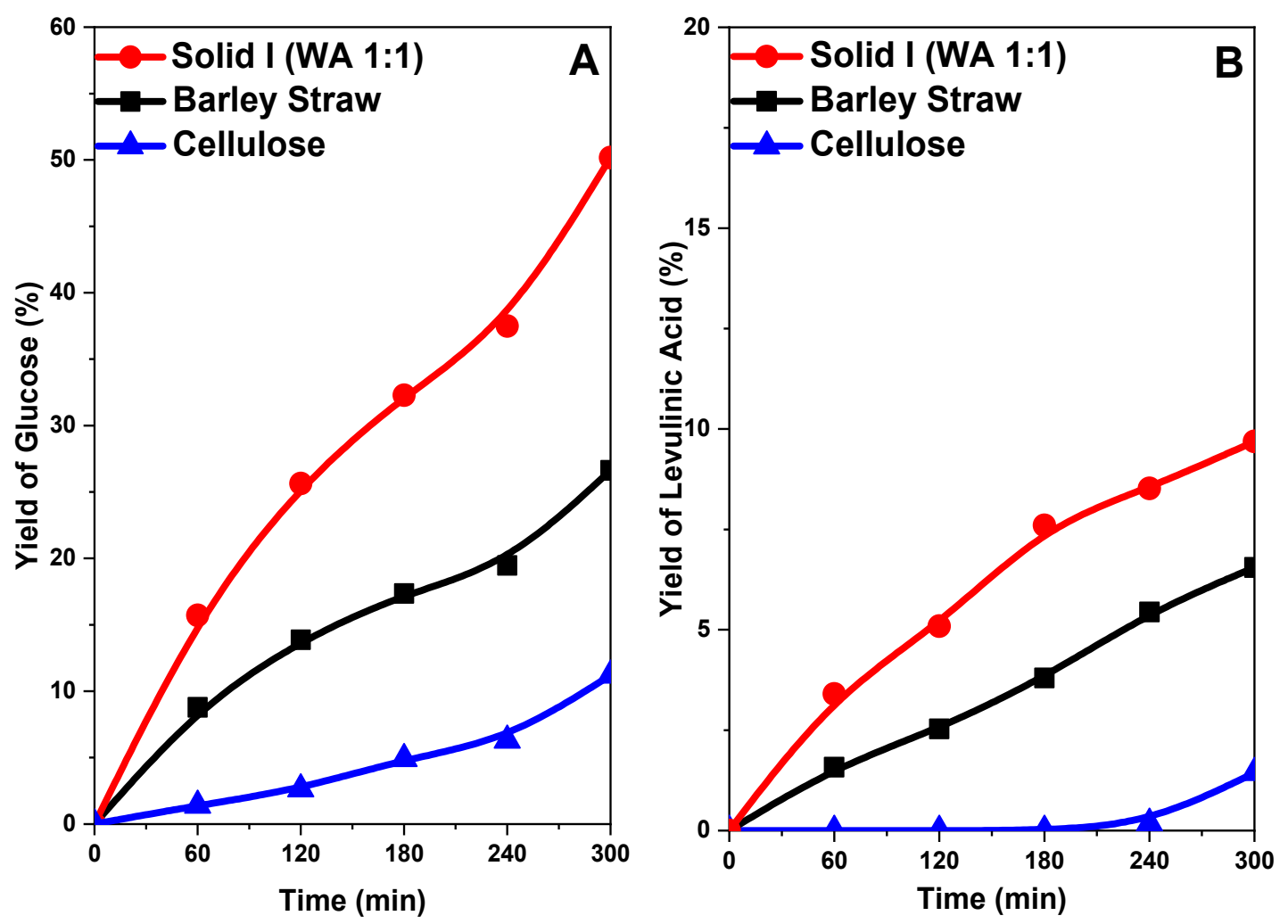

Figure 12. Yield of glucose (A) and levulinic acid (B) from the hydrolysis of cellulose, untreated barley straw and barley straw treated (Solid I) with [EMIMAcO].

The yield of levulinic acid follows a profile very similar to that of glucose (Figure 12B) because levulinic acid is a byproduct of glucose; therefore, at higher glucose concentrations, more levulinic acid can be formed, but in all cases, the yield of levulinic acid is low with respect to that of glucose.

We compared the raw barley straw sample without treatment and Solid I in acid hydrolysis to obtain the concentration curves of the compounds xylose and furfural (Figure 13A,B) in both cases. The yield of xylose increased quickly with reaction time, reaching a maximum in both cases (Figure 13A). At $2 \mathrm{~h}$, the barley straw obtained a yield of $45 \%$, and Solid I achieved a yield of $58 \%$, but the yield of Solid I reached a maximum of $60 \%$ at $3 \mathrm{~h}$ and then decreased until the end of the reaction, at which point the yield of xylose was $25 \%$ in barley straw and 35\% in Solid I. This fact indicates that the pretreated sample (Solid I) can more easily hydrolyze hemicellulose, obtaining a higher yield of xylose more quickly, although the differences are less evident than with glucose (Figure 12A). This is because hemicellulose (polymer of origin of xylose) is much easier to hydrolyze than glucose and, therefore, even without treatment, hydrolysis can be effectively performed. In addition, presenting behavior typical of an intermediate reaction compound in consecutive reactions, the source of the 
xylose is consumed when in contact with the acid catalyst in the medium; then, dehydration takes place, and the material is transformed into furfural (Figure 13B).
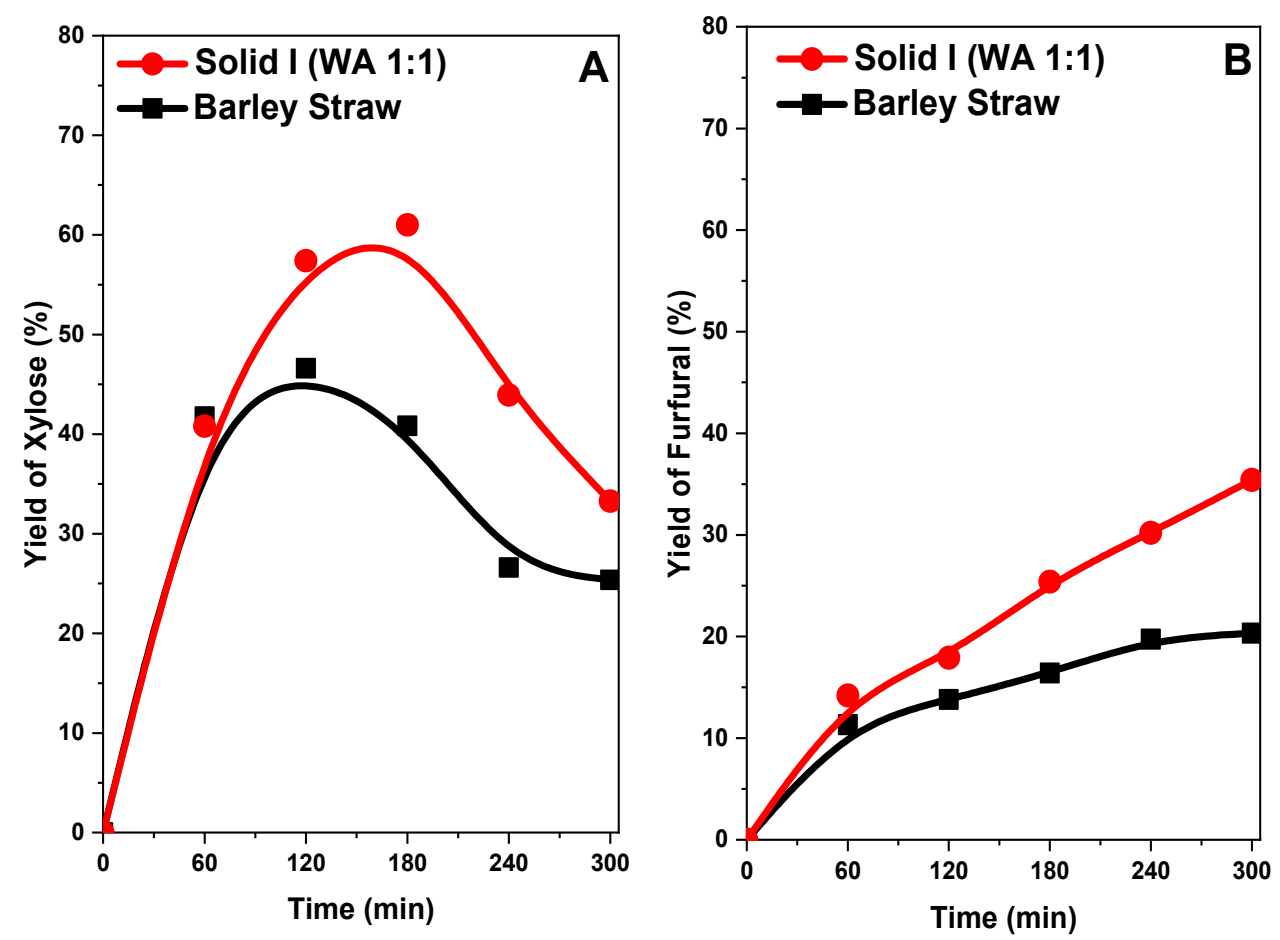

Figure 13. Yields of xylose (A) and furfural (B) of barley straw treated and not treated with [EMIMAcO]

The furfural yield profiles indicate that the yield increases with reaction time, reaching, $36 \%$ with Solid I and $20 \%$ with untreated barley straw at $5 \mathrm{~h}$. The Solid I sample had a higher concentration because the xylose concentration was higher than in the untreated sample.

In the hydrolysis process, the polymeric chains of cellulose and hemicellulose become smaller, and some of them become soluble in water; therefore, the reaction medium not only contains monomers such as glucose or xylose but can also contain oligomers with several units that are soluble. For this reason, we analyzed the final reaction samples and calculated the total reducing sugars (TRS) content, including the sugars in monomeric and oligomeric forms. The obtained results are shown in Table 4. The values of TRS are clearly higher than those obtained by the sum of sugars measured with HPLC (monomeric), which indicates that in the reaction medium, there is an appreciable amount of oligomeric sugars; this discrepancy is more evident for straw samples (original and Solid I). The yield to sugars decreases according to the order Solid I > original barley straw $>$ cellulose, which coincides with the conversion values described in Table 3. However, the selectivity of total reducing sugars does not follow this trend (Table 4). It is clear that the selectivity of TRS is much higher for the Solid I sample than the untreated samples of cellulose and barley straw. The combination of high conversion and high selectivity in the Solid I sample produced one of the highest sugar yields in acid catalyzed hydrolysis of lignocellulosic biomass among those described in the literature [72-78].

Table 4. Total reducing sugars (TRS) measurements obtained from the samples after the hydrolysis reaction.

\begin{tabular}{ccccc}
\hline Sample & TRS (g/L) & $\begin{array}{c}\text { \% Yield of Sugars } \\
\text { (TRS) }\end{array}$ & $\begin{array}{c}\text { \% Selectivity of } \\
\text { Sugars (TRS) }\end{array}$ & $\begin{array}{c}\text { Total Monomeric } \\
\text { Sugars (g/L) }\end{array}$ \\
\hline Cellulose & 1.7 & 15 & 60 & 1.5 \\
Barley Straw & 2.9 & 45 & 54 & 1.8 \\
Solid I (WA 1:1) & 6.1 & 72 & 80 & 3.4 \\
\hline
\end{tabular}




\section{Conclusions}

Dissolution of barley straw in [EMIMAcO] and subsequent precipitation with water:acetone mixtures can be employed in the fragmentation of the main components. A wateracetone ratio of 1:1 is optimal for the efficient separation of carbohydrates with respect to lignin, with a high biomass recovery efficiency of approximately $90 \%$ with respect to the initial sample. The first precipitate (Solid I) is clearly enriched in carbohydrates (cellulose and hemicellulose), and the second precipitate is a lignin-rich solid, as evidenced by IR and NMR. The enriched carbohydrate solid (Solid I) presented large changes in structure (SEM) and crystallinity (XRD) with respect to those of the original barley straw. This carbohydrate-rich fraction is easier to hydrolyze, with a yield of total reducing sugars that is among the highest described in the literature.

Author Contributions: Experimental work: M.L.-S. and S.M.-d.; supervision: S.M.-d. and J.M.C.-M.; writing-original draft preparation: M.L.-S. and S.M.-d.; writing—review and editing: J.M.C.-M. and J.L.G.F.

Funding: This research was funded by Comunidad de Madrid (Spain) and ERDF (European Regional Development Fund), grant numbers S2013/MAE-2882 (RESTOENE-2-CM), S2018/EMT-4344 (BIOTRES-CM) and CSIC (201880E029). M.L.-S. acknowledges the support of the European Social Fund and Community of Madrid for her contract.

Conflicts of Interest: The authors declare no conflict of interest.

\section{References}

1. Scarlat, N.; Dallemand, J.F.; Monforti-Ferrario, F.; Nita, V. The role of biomass and bioenergy in a future bioeconomy: Policies and facts. Environ. Dev. 2015, 15, 3-34. [CrossRef]

2. Pickett, J. Sustainable Biofuels: Prospects and Challenge; The Royal Society: London, UK, 2018.

3. Scheller, H.V.; Ulvskov, P. Hemicelluloses. Annu. Rev. Plant Biol. 2010, 61, 263-289. [CrossRef] [PubMed]

4. Rubin, E.M. Genomics of cellulosic biofuels. Nature 2008, 454, 841-845. [CrossRef]

5. Karimi, K.; Taherzadeh, M.J. A critical review of analytical methods in pretreatment of lignocelluloses: Composition, imaging, and crystallinity. Bioresour. Technol. 2016, 200, 1008-1018. [CrossRef] [PubMed]

6. O'Sullivan, A.C. Cellulose: The structure slowly unravels. Cellulose 1997, 4, 173-207. [CrossRef]

7. Sharples, A. The hydrolysis of cellulose and its relation to structure. Part 2. Trans. Faraday Soc. 1958, 54, 913-917. [CrossRef]

8. Sharples, A. The hydrolysis of cellulose and its relation to structure. Trans. Faraday Soc. 1957, 53, $1003-1013$. [CrossRef]

9. Pérez, J.; Muñoz-Dorado, J.; Rubia, T.D.L.; Martı́nez, J. Biodegradation and biological treatments of cellulose, hemicellulose and lignin: An overview. Int. Microbiol. 2002, 5, 53-63. [CrossRef]

10. Alvira, P.; Tomas-Pejo, E.; Ballesteros, M.; Negro, M.J. Pretreatment technologies for an efficient bioethanol production process based on enzymatic hydrolysis: A review. Bioresour. Technol. 2010, 101, 4851-4861. [CrossRef]

11. Zakzeski, J.; Bruijnincx, P.C.A.; Jongerius, A.L.; Weckhuysen, B.M. The Catalytic Valorization of Lignin for the Production of Renewable Chemicals. Chem. Rev. 2010, 110, 3552-3599. [CrossRef]

12. Mosier, N.; Wyman, C.; Dale, B.; Elander, R.; Lee, Y.Y.; Holtzapple, M.; Ladisch, M. Features of promising technologies for pretreatment of lignocellulosic biomass. Bioresour. Technol. 2005, 96, 673-686. [CrossRef]

13. Hendriks, A.T.W.M.; Zeeman, G. Pretreatments to enhance the digestibility of lignocellulosic biomass. Bioresour. Technol. 2009, 100, 10-18. [CrossRef]

14. Yi, Z.; Pan, Z.P.; Zhang, R.H. Overview of biomass pretreatment for cellulosic ethanol production. Int. J. Agric. Biol. Eng. 2009, 2, 51-68.

15. FitzPatrick, M.; Champagne, P.; Cunningham, M.F.; Whitney, R.A. A biorefinery processing perspective: Treatment of lignocellulosic materials for the production of value-added products. Bioresour. Technol. 2010, 101, 8915-8922. [CrossRef]

16. Karimi, K.; Taherzadeh, M.J. A critical review on analysis in pretreatment of lignocelluloses: Degree of polymerization, adsorption/desorption, and accessibility. Bioresour. Technol. 2016, 203, 348-356. [CrossRef] 
17. Oliva, J.; Negro, M.; Manzanares, P.; Ballesteros, I.; Chamorro, M.; Sáez, F.; Ballesteros, M.; Moreno, A. A Sequential Steam Explosion and Reactive Extrusion Pretreatment for Lignocellulosic Biomass Conversion within a Fermentation-Based Biorefinery Perspective. Fermentation 2017, 3, 15. [CrossRef]

18. Sipponen, M.H.; Pihlajaniemi, V.; Pastinen, O.; Laakso, S. Reduction of surface area of lignin improves enzymatic hydrolysis of cellulose from hydrothermally pretreated wheat straw. RSC Adv. 2014, 4, 36591-36596. [CrossRef]

19. Pihlajaniemi, V.; Sipponen, M.H.; Liimatainen, H.; Sirvio, J.A.; Nyyssola, A.; Laakso, S. Weighing the factors behind enzymatic hydrolyzability of pretreated lignocellulose. Green Chem. 2016, 18, 1295-1305. [CrossRef]

20. Xu, H.; Li, B.; Mu, X. Review of Alkali-Based Pretreatment to Enhance Enzymatic Saccharification for Lignocellulosic Biomass Conversion. Ind. Eng. Chem. Res. 2016, 55, 8691-8705. [CrossRef]

21. Kim, S.; Dale, B.E. Global potential bioethanol production from wasted crops and crop residues. Biomass Bioenergy 2004, 26, 361-375. [CrossRef]

22. Gupta, A.; Verma, J.P. Sustainable bio-ethanol production from agro-residues: A review. Renew. Sustain. Energy Rev. 2015, 41, 550-567. [CrossRef]

23. Searle, S.; Malins, C. Availability of Cellulosic Residues and Wastes in the EU; The International Council on Clean Transportation (ICCT): Washington, DC, USA, 2013.

24. Kilpeläinen, I.; Xie, H.; King, A.; Granstrom, M.; Heikkinen, S.; Argyropoulos, D.S. Dissolution of Wood in Ionic Liquids. J. Agric. Food. Chem. 2007, 55, 9142-9148. [CrossRef]

25. Kosan, B.; Michels, C.; Meister, F. Dissolution and forming of cellulose with ionic liquids. Cellulose 2007, 15, 59-66. [CrossRef]

26. Zakrzewska, M.E.; Bogel-Łukasik, E.; Bogel-Łukasik, R. Solubility of Carbohydrates in Ionic Liquids. Energy Fuels 2010, 24, 737-745. [CrossRef]

27. Mora-Pale, M.; Meli, L.; Doherty, T.V.; Linhardt, R.J.; Dordick, J.S. Room temperature ionic liquids as emerging solvents for the pretreatment of lignocellulosic biomass. Biotechnol. Bioeng. 2011, 108, 1229-1245. [CrossRef] [PubMed]

28. Muhammad, N.; Man, Z.; Bustam Khalil, M.A. Ionic liquid-a future solvent for the enhanced uses of wood biomass. Eur. J. Wood Wood Prod. 2011, 70, 1-9. [CrossRef]

29. Tadesse, H.; Luque, R. Advances on biomass pretreatment using ionic liquids: An overview. Energy Environ. Sci. 2011, 4, 3913-3929. [CrossRef]

30. Wang, H.; Gurau, G.; Rogers, R.D. Ionic liquid processing of cellulose. Chem. Soc. Rev. 2012, 41, $1519-1537$. [CrossRef]

31. Minnick, D.L.; Flores, R.A.; DeStefano, M.R.; Scurto, A.M. Cellulose Solubility in Ionic Liquid Mixtures: Temperature, Cosolvent, and Antisolvent Effects. J. Phys. Chem. B 2016, 120, 7906-7919. [CrossRef]

32. Xu, J.; Liu, B.; Hou, H.; Hu, J. Pretreatment of eucalyptus with recycled ionic liquids for low-cost biorefinery. Bioresour. Technol. 2017, 234, 406-414. [CrossRef]

33. Morales-delaRosa, S.; Campos-Martin, J.M.; Fierro, J.L.G. Complete Chemical Hydrolysis of Cellulose into Fermentable Sugars through Ionic Liquids and Antisolvent Pretreatments. ChemSusChem 2014, 7, 3467-3475. [CrossRef]

34. Morales-delaRosa, S.; Campos-Martin, J.M.; Fierro, J.L.G. Chemical hydrolysis of cellulose into fermentable sugars through ionic liquids and antisolvent pretreatments using heterogeneous catalysts. Catal. Today 2018, 302, 87-93. [CrossRef]

35. Lan, W.; Liu, C.F.; Sun, R.C. Fractionation of bagasse into cellulose, hemicelluloses, and lignin with ionic liquid treatment followed by alkaline extraction. J. Agric. Food Chem. 2011, 59, 8691-8701. [CrossRef]

36. Da Costa Lopes, A.M.; João, K.G.; Rubik, D.F.; Bogel-Łukasik, E.; Duarte, L.C.; Andreaus, J.; Bogel-Łukasik, R. Pre-treatment of lignocellulosic biomass using ionic liquids: Wheat straw fractionation. Bioresour. Technol. 2013, 142, 198-208. [CrossRef]

37. Yang, D.; Zhong, L.-X.; Yuan, T.-Q.; Peng, X.-W.; Sun, R.-C. Studies on the structural characterization of lignin, hemicelluloses and cellulose fractionated by ionic liquid followed by alkaline extraction from bamboo. Ind. Crops Prod. 2013, 43, 141-149. [CrossRef]

38. Yang, X.; Wang, Q.; Yu, H. Dissolution and regeneration of biopolymers in ionic liquids. Russ. Chem. Bull. 2014, 63, 555-559. [CrossRef]

39. Zhang, P.; Dong, S.J.; Ma, H.H.; Zhang, B.X.; Wang, Y.F.; Hu, X.M. Fractionation of corn stover into cellulose, hemicellulose and lignin using a series of ionic liquids. Ind. Crops Prod. 2015, 76, 688-696. [CrossRef] 
40. Morais, A.R.C.; Pinto, J.V.; Nunes, D.; Roseiro, L.B.; Oliveira, M.C.; Fortunato, E.; Bogel-Łukasik, R. Imidazole: Prospect Solvent for Lignocellulosic Biomass Fractionation and Delignification. ACS Sustain. Chem. Eng. 2016, 4, 1643-1652. [CrossRef]

41. Mohtar, S.S.; Tengku Malim Busu, T.N.; Md Noor, A.M.; Shaari, N.; Mat, H. An ionic liquid treatment and fractionation of cellulose, hemicellulose and lignin from oil palm empty fruit bunch. Carbohydr. Polym. 2017, 166, 291-299. [CrossRef]

42. Sathitsuksanoh, N.; George, A.; Zhang, Y.H.P. New lignocellulose pretreatments using cellulose solvents: A review. J. Chem. Technol. Biotechnol. 2013, 88, 169-180. [CrossRef]

43. Zhu, S.; Wu, Y.; Chen, Q.; Yu, Z.; Wang, C.; Jin, S.; Ding, Y.; Wu, G. Dissolution of cellulose with ionic liquids and its application: A mini-review. Green Chem. 2006, 8, 325-327. [CrossRef]

44. Haghighi Mood, S.; Hossein Golfeshan, A.; Tabatabaei, M.; Salehi Jouzani, G.; Najafi, G.H.; Gholami, M.; Ardjmand, M. Lignocellulosic biomass to bioethanol, a comprehensive review with a focus on pretreatment. Renew. Sustain. Energy Rev. 2013, 27, 77-93. [CrossRef]

45. Brodeur, G.; Yau, E.; Badal, K.; Collier, J.; Ramachandran, K.B.; Ramakrishnan, S. Chemical and physicochemical pretreatment of lignocellulosic biomass: A review. Enzym. Res. 2011, 2011. [CrossRef]

46. Morales-delaRosa, S.; Campos-Martin, J.M.; Fierro, J.L.G. High glucose yields from the hydrolysis of cellulose dissolved in ionic liquids. Chem. Eng. J. 2012, 181, 538-541. [CrossRef]

47. Lara-Serrano, M.; Sáez Angulo, F.; Negro, M.J.; Morales-delaRosa, S.; Campos-Martin, J.M.; Fierro, J.L.G. Second-Generation Bioethanol Production Combining Simultaneous Fermentation and Saccharification of IL-Pretreated Barley Straw. ACS Sustain. Chem. Eng. 2018, 6, 7086-7095. [CrossRef]

48. Fort, D.A.; Remsing, R.C.; Swatloski, R.P.; Moyna, P.; Moyna, G.; Rogers, R.D. Can ionic liquids dissolve wood? Processing and analysis of lignocellulosic materials with 1-n-butyl-3-methylimidazolium chloride. Green Chem. 2007, 9, 63-69. [CrossRef]

49. Huddleston, J.G.; Visser, A.E.; Reichert, W.M.; Willauer, H.D.; Broker, G.A.; Rogers, R.D. Characterization and comparison of hydrophilic and hydrophobic room temperature ionic liquids incorporating the imidazolium cation. Green Chem. 2001, 3, 156-164. [CrossRef]

50. Sun, N.; Rahman, M.; Qin, Y.; Maxim, M.L.; Rodríguez, H.; Rogers, R.D. Complete dissolution and partial delignification of wood in the ionic liquid 1-ethyl-3-methylimidazolium acetate. Green Chem. 2009, 11, 646-655. [CrossRef]

51. Sun, N.; Rodriguez, H.; Rahman, M.; Rogers, R.D. Where are ionic liquid strategies most suited in the pursuit of chemicals and energy from lignocellulosic biomass? Chem. Commun. 2011, 47, 1405-1421. [CrossRef]

52. Swatloski, R.P.; Spear, S.K.; Holbrey, J.D.; Rogers, R.D. Dissolution of Cellose with Ionic Liquids. J. Am. Chem. Soc. 2002, 124, 4974-4975. [CrossRef]

53. Sheldon, R.A. Green and sustainable manufacture of chemicals from biomass: State of the art. Green Chem. 2014, 16, 950-963. [CrossRef]

54. Prasad, K.; Sharma, M. Green solvents for the dissolution and processing of biopolymers. Curr. Opin. Green Sustain. Chem. 2019, 18, 72-78. [CrossRef]

55. Wang, H.; Gurau, G.; Pingali, S.V.; O’Neill, H.M.; Evans, B.R.; Urban, V.S.; Heller, W.T.; Rogers, R.D. Physical Insight into Switchgrass Dissolution in Ionic Liquid 1-Ethyl-3-methylimidazolium Acetate. ACS Sustain. Chem. Eng. 2014, 2, 1264-1269. [CrossRef]

56. NREL. N.R.E.L. Biomass Compositional Analysis Laboratory Procedures. Available online: https://www. nrel.gov/bioenergy/biomass-compositional-analysis.html (accessed on 1 March 2019).

57. Morales-delaRosa, S.; Campos-Martin, J.M.; Fierro, J.L.G. Optimization of the process of chemical hydrolysis of cellulose to glucose. Cellulose 2014, 21, 2397-2407. [CrossRef]

58. Morales-delaRosa, S.; García Fierro, J.L.; Campos-Martín, J.M. Method for the Hydrolysis of Lignocellulosic Biomass. Patent WO2015/004296, 15 January 2015.

59. Capel-Sanchez, M.C.; Barrio, L.; Campos-Martin, J.M.; Fierro, J.L.G. Silylation and surface properties of chemically grafted hydrophobic silica. J. Colloid Interface Sci. 2004, 277, 146-153. [CrossRef]

60. Pandey, K.K.; Pitman, A.J. FTIR studies of the changes in wood chemistry following decay by brown-rot and white-rot fungi. Int. Biodeterior. Biodegrad. 2003, 52, 151-160. [CrossRef]

61. Hergert, H.L. Infrared Spectra of Lignin and Related Compounds. II. Conifer Lignin and Model Compounds1,2. J. Org. Chem. 1960, 25, 405-413. [CrossRef] 
62. Sun, R.; Hughes, S. Fractional extraction and physico-chemical characterization of hemicelluloses and cellulose from sugar beet pulp. Carbohydr. Polym. 1998, 36, 293-299. [CrossRef]

63. Sun, X.F.; Xu, F.; Sun, R.C.; Geng, Z.C.; Fowler, P.; Baird, M.S. Characteristics of degraded hemicellulosic polymers obtained from steam exploded wheat straw. Carbohydr. Polym. 2005, 60, 15-26. [CrossRef]

64. Kakuchi, R.; Yamaguchi, M.; Endo, T.; Shibata, Y.; Ninomiya, K.; Ikai, T.; Maeda, K.; Takahashi, K. Efficient and rapid direct transesterification reactions of cellulose with isopropenyl acetate in ionic liquids. RSC Adv. 2015, 5, 72071-72074. [CrossRef]

65. Wan Daud, W.R.; Djuned, F.M. Cellulose acetate from oil palm empty fruit bunch via a one step heterogeneous acetylation. Carbohydr. Polym. 2015, 132, 252-260. [CrossRef]

66. Korbag, I.; Mohamed Saleh, S. Studies on the formation of intermolecular interactions and structural characterization of polyvinyl alcohol/lignin film. Int. J. Environ. Stud. 2016, 73, 226-235. [CrossRef]

67. Toledano, A.; Serrano, L.; Garcia, A.; Mondragon, I.; Labidi, J. Comparative study of lignin fractionation by ultrafiltration and selective precipitation. Chem. Eng. J. 2010, 157, 93-99. [CrossRef]

68. French, A.; Santiago Cintrón, M. Cellulose polymorphy, crystallite size, and the Segal Crystallinity Index. Cellulose 2013, 20, 583-588. [CrossRef]

69. Singh, S.; Simmons, B.A.; Vogel, K.P. Visualization of biomass solubilization and cellulose regeneration during ionic liquid pretreatment of switchgrass. Biotechnol. Bioeng. 2009, 104, 68-75. [CrossRef] [PubMed]

70. Kumar, R.; Mago, G.; Balan, V.; Wyman, C.E. Physical and chemical characterizations of corn stover and poplar solids resulting from leading pretreatment technologies. Bioresour. Technol. 2009, 100, 3948-3962. [CrossRef] [PubMed]

71. Morales-delaRosa, S.; Campos-Martin, J.M.; Fierro, J.L.G. Procedimiento de Hidrólisis de Biomasa Lignocelulósica. Patent ES2528394, 9 February 2015.

72. Vanoye, L.; Fanselow, M.; Holbrey, J.D.; Atkins, M.P.; Seddon, K.R. Kinetic model for the hydrolysis of lignocellulosic biomass in the ionic liquid, 1-ethyl-3-methyl-imidazolium chloride. Green Chem. 2009, 11, 390-396. [CrossRef]

73. Schneider, L.; Haverinen, J.; Jaakkola, M.; Lassi, U. Solid acid-catalyzed depolymerization of barley straw driven by ball milling. Bioresour. Technol. 2016, 206, 204-210. [CrossRef] [PubMed]

74. Bai, C.; Zhu, L.; Shen, F.; Qi, X. Black liquor-derived carbonaceous solid acid catalyst for the hydrolysis of pretreated rice straw in ionic liquid. Bioresour. Technol. 2016, 220, 656-660. [CrossRef]

75. Vu, A.; Wickramasinghe, S.R.; Qian, X. Polymeric Solid Acid Catalysts for Lignocellulosic Biomass Fractionation. Ind. Eng. Chem. Res. 2018, 57, 4514-4525. [CrossRef]

76. Si, W.; Li, Y.; Zheng, J.; Wei, S.A.; Wang, D. Enhanced hydrolysis of bamboo biomass by chitosan based solid acid catalyst with surfactant addition in ionic liquid. Carbohydr. Polym. 2017, 174, 154-159. [CrossRef]

77. Kassaye, S.; Pant, K.K.; Jain, S. Hydrolysis of cellulosic bamboo biomass into reducing sugars via a combined alkaline solution and ionic liquid pretreament steps. Renew. Energy 2017, 104, 177-184. [CrossRef]

78. Liang, J.; Chen, X.; Wang, L.; Wei, X.; Wang, H.; Lu, S.; Li, Y. Subcritical carbon dioxide-water hydrolysis of sugarcane bagasse pith for reducing sugars production. Bioresour. Technol. 2017, 228, 147-155. [CrossRef]

(C) 2019 by the authors. Licensee MDPI, Basel, Switzerland. This article is an open access article distributed under the terms and conditions of the Creative Commons Attribution (CC BY) license (http://creativecommons.org/licenses/by/4.0/). 